\title{
A phenomenological study on the meaning of presence of elderly participants in an exercise-music program
}

\author{
Kyungsun $\mathrm{Kim}^{\mathrm{a}(\mathbb{1}}$, Hyeoncheol Jeong ${ }^{\mathrm{b}(\mathbb{1})}$ \\ ${ }^{a}$ Department of Nursing, Kyungbuk College, Yeongju, Republic of Korea \\ ${ }^{b}$ Department of Nursing, Sahmyook University, Seoul, Republic of Korea
}

\begin{abstract}
Objective: The reason why it is important to look at the benefits of exercise-music experience perceived by the elderly is that the satisfaction of life in old age is a meaningful reflection of the subjective perception of the life of the elderly. This is because it must be understood as the center.

Design: A qualitative study.

Methods: Participants are senior citizens attending senior citizens' college located in Eumseong city. Those who have taken an exercise-music song program for at least one semester served as the participants. Individual interviews were conducted by selecting 10 people through purposeful sampling. The collected data were analyzed by applying Colaizzi's method among phenomenological methods. The exercise-music program was conducted for 12 weeks, for a total of 50 minutes for each time (10 minutes for introduction, 35 minutes for music, 5 minutes for finishing).

Results: As a result of the study, the experience of the exercise-music program was derived into 6 categories and 13 subjects. These 6 main categories are 'Changes from the developmental crisis', 'Freedom from the confines of others', 'Positive emotions found through songs', 'Feeling of peer and fellowship relationships', 'Changes in self-awareness', It appeared as a 'Change in the way of life'.

Conclusions: In conclusion, the experience of the exercise-music program brought about a positive changes in life of doing one's best by improving confidence and confirming presence. Therefore, this study suggests activation of senior college programs to find a sense of presence for each level by using exercise-music programs with good accessibility.
\end{abstract}

Key Words: Aged, Exercise, Music therapy, Qualitative research

\section{Introduction}

As of 2020, the proportion of the elderly people aged 65 years or older entered the aging society at $15.7 \%$ of the total population, and it is estimated that the proportion of the elderly population will increase to $20.3 \% 5$ years later in 2025 [1]. As such, the aging population of Korea is progressing at a fairly rapid pace, and various types of social problems, including support for the elderly, are being caused by the expansion of social roles and changes in family functions, which are the most striking features in the elderly society. It is becoming an increasingly important task to solve these problems at the social and national level [2].
Old age is a time when there are more lost roles than any other stage in life development [3], and as aging progresses, psychological and emotional changes such as lack of confidence, passivity, and introversion can lead to depression. The elderly's physical changes, loss of sensory and cognitive function, loss of family and friends, social interactions, and decreased ability and control of the elderly reduce their satisfaction with their own life and also lowers the elderly's potential self-esteem, which becomes a factor [2]. Therefore, it is necessary to improve the elderly's self-esteem by helping the elderly to positively accept physical and mental aging and by changing the negative stereotypes of others about the elderly [3]. On the other hand, the quality of life with old

Received: 2 December, 2020 Revised: 29 December, 2020 Accepted: 29 December, 2020

Corresponding author: Hyeoncheol Jeong (ORCID https://orcid.org/0000-0001-8606-2373)

Department of Nursing, Sahmyook University, 815 Hwarang-ro, Nowon-gu, Seoul 01795, Republic of Korea

Tel: 82-2-3399-1592 Fax: 82-2-3399-1593 E-mail: love2hc@syu.ac.kr

(c) This is an Open-Access article distributed under the terms of the Creative Commons Attribution Non-Commercial License (http://creativecommons.org/licenses/ by-nc/4.0) which permits unrestricted non-commercial use, distribution, and reproduction in any medium, provided the original work is properly cited.

Copyright @ 2020 Korean Academy of Physical Therapy Rehabilitation Science 
age is very important in grasping an individual's successful life because it is directly linked to the happiness of the elderly and the achievement of life goals. In particular, as we enter the time of aging, the focus is living well and healthy rather than how long the elderly live. Improving the quality of life of the elderly is directly related to successful aging, a state in which the elderly can satisfy themselves and those around them physically, socially, and psychologically by discovering their potential $[4,5]$. Therefore, it is necessary to create personal and environmental conditions for the elderly to live with the greatest satisfaction and happiness in their lives.

Kong and Lee [3] reported that the elderly's continuous activities are closely related to the elderly's self-esteem. The various programs of community senior colleges can provide opportunities to promote leisure activities for the elderly, promote physical health, and sustain social relationships. In addition, it has a positive aspect of integrating the elderly in the community by forming a support network that can not only satisfy individual needs, such as maintaining and developing mental health, but also to form intimacy, which has a significant impact on improving the quality of life of the elderly [6]. Active participation in such leisure activities in the elderly relieves the feeling of loneliness caused by the loss of roles in the elderly, and furthermore, it becomes an opportunity for self-esteem and self-realization, enabling them to pursue life satisfaction in the elderly [7].

The most common and preferred leisure activities among the elderly are programs using music such as singing and playing musical instruments [8,9], and participation in music activities has been reported to elicit positive emotional responses to the elderly [10]. In addition, the music program grafted with rhythm can participate in various levels and forms according to the individual characteristics of the elderly, and can help in pursuing a vibrant and valuable life, inducing active use of body and cognition, and the quality of life can be improved by meeting different people [11].

In previous studies related to music programs for the elderly, the elderly were receiving emotional help by using music appreciation as a strategy for emotional control, identity, and belonging [12], and various types of exercise programs, rhythms, and songs within the community. The elderly who participate in activities such as singing and playing musical instruments were prevented from depression and their physical health was maintained, thereby improving their quality of life [13].

These preceding studies showed that the elderly per- ceived benefits in various areas through participation in musical activities, and the benefits of these experiences were related to positive life satisfaction with old age. As such, it is important to look at the benefits of exercise-music experience perceived by the elderly. As satisfaction with life in old age is a meaningful reflection of the subjective perception of the life of the elderly, the exercise-music experience of the elderly is also subjective. This is because it must be understood based on perspective. Therefore, this study aimed to understand the meaning and essence of the sense of existence inherent in their experiences by understanding the motivation and meaning of participation in the sports-music program of the senior citizens from their perspective.

\section{Methods}

This study is a qualitative study that applied Colaizzi's phenomenological research method to understand and explain the meaning of the elderly's experience of the exercise-music program of a senior citizens' college.

\section{Participants}

Participants in this study were senior citizens attending a senior citizens' college located in Eumseong city. After explaining the purpose and process of this study to the dean of the senior citizens' college, they asked for cooperation and then openly recruited for subjects. An additional explanation was given to the applicants, and consent and signature were obtained to participate in the study. As for the selection method, 10 subjects who had no problem in cognitive function and were able to communicate among the students who took the exercise-music song program for more than one semester were selected as the appropriate number for phenomenological qualitative research [14].

\section{Ethical considerations}

This study was embarked after receiving approval by the Sahmyook University's IRB (2-7001793-AB-N-012020011 $\mathrm{HR})$. Prior to data collection, this study received consent from the participants for the purpose and method of research, confidentiality and anonymity of personal information, and voluntary participation. The researcher explained that the collected data will be used only for research purposes and that the data will be discarded after storage for 3 years after the end of the study. In addition, it was explained in advance that the interview could be stopped at any time during the interview and that questions that are difficult 
to answer during the interview did not have to be answered. Participants were provided with a small gift in return.

\section{Intervention}

\section{Exercise-music program}

The exercise-music program was conducted for 12 weeks, for a total of 50 minutes for each time (10 minutes for introduction, 35 minutes for music, 5 minutes for finishing). The program content was as follows: 1) In the introduction exercise, I did a simple bare-handed exercise; 2) In music activities, many people had time to select songs they had heard or sung and sang them together. Only applicants had time to show off their songs. Talking about the objects and contents in the lyrics made me feel a bond with the students; 3) The finishing exercise always made physical contact with each other such as holding hands and tapping on the back (Table 1).

\section{Data collection}

Data collection for this study was interviewed from March 31, 2019 to December 1, 2019. In order to prevent the recent epidemic of Coronavirus Disease-19 (COVID-19) infection, the study subjects were asked whether they had respiratory symptoms, were assessed for fever, and then only nurses without symptoms conducted hand hygiene and hand disinfection before participating in the study. The participants and the researcher practiced hand sanitization and by carrying hand sanitizing gel whenever necessary, wore health masks, and then the study was conducted at the designated areas for the subjects in order to while adhere to the principles for social distancing. Researchers who did not educate the elderly, who were participants, and who were not in charge of evaluation conducted interviews to ensure freedom and allow the participants freedom of expression. The

Table 1. Exercise-music program

\begin{tabular}{|c|c|c|}
\hline Category & Content & $\begin{array}{l}\text { Time } \\
(\min )\end{array}$ \\
\hline $\begin{array}{l}\text { Introduction } \\
\text { exercise }\end{array}$ & - Warm up with bare-handed gymnastics & 10 \\
\hline $\begin{array}{l}\text { Music } \\
\text { activity }\end{array}$ & $\begin{array}{l}\text { - Select songs you know and sing them } \\
\text { together }\end{array}$ & 35 \\
\hline \multirow{2}{*}{$\begin{array}{r}\text { Finishing } \\
\text { exercise }\end{array}$} & - Come to the front and show off singing & 5 \\
\hline & $\begin{array}{l}\text { Learning the meaning of the lyrics } \\
\text { Holding hands } \\
\text { Pat on the back }\end{array}$ & \\
\hline
\end{tabular}

interview was conducted with 10 people in a one-to-one interview in order to derive a general understanding of the process of common experience among the participants. The interview location was conducted at a place chosen by the participant so that participants could talk comfortably at the place they wanted and was mainly conducted in a quiet and closed place in the consultation room and break room designated by the participant. Through one-on-one interviews, the semi-structured, open- ended question, 'What is the experience of the elderly who participated in the movement-musical singing department at the senior citizens' college?' allowed participants to freely interview and to fully discuss their experiences. This was done until the participant's story was repeated or until it became saturated with no more new stories. In addition, after transcribing the contents of the 1st interview, additional 2nd interviews were conducted for insufficient contents of the interview, or if the interview was difficult, the interview was conducted by phone or text message. All interview contents were recorded, and after the interview, the recorded contents were entered into a computer and were transcribed. After that, while reading the manuscript, the researcher confirmed whether it was consistent with the interview content and analyzed it as follows. The time required for 1 interview for each subject ranged from 30 minutes to 1 hour.

\section{Data analysis}

The data collected for the analysis of this study were analyzed using the phenomenological 7-step method suggested by Colaizzi in order to grasp the essential themes of the elderly's exercise-musical singing experience. In the 1st step, we listened to the recorded content several times, recalled the interview situation, and transcribed the subject's statement in order to grasp the overall meaning. In the 2nd step, a meaningful statement was derived from the content that was judged to be deeply related to the content phenomenon that is repeatedly displayed or emphasized in the subjects' statements. In the 3rd step, a general and abstract statement was made from the extracted sentence or phrase, and the meaning was reconstructed in the language of the researcher. In step 4, general and abstract statements were analyzed and classified into subject, subject collection, and category. In step 5, the analyzed data, that is, the subject, the subject collection, and the categories were described collectively. Step 6 was described as a whole and stated the essential structure of the subjects' experiences, centering on the common elements of the investigated phenomenon. Step 
7 went through the validity of confirming with the subjects that the final description was consistent with the experiences of 10 subjects.

\section{Results}

As a result of analyzing the meaning of the elderly's experience of participating in the elderly college exercise-music program, 6 categories and 13 themes were derived. The 6 main categories were 'Changes in the developmental crisis.', 'Freedom from the confines of others.', 'Positive emotions found by songs.', 'Feeling the relationship with peers.', 'Changes in self-awareness.', it appeared as 'Change of way of life'. The specific experience is shown in Table 2.

\section{Discussion}

This study was conducted to gain a holistic understanding

Table 2. Category and theme of exercise-music program

\begin{tabular}{|c|c|c|}
\hline \multicolumn{3}{|c|}{ Exercise-music program } \\
\hline Category & Theme cluster & Theme \\
\hline \multirow[t]{4}{*}{$\begin{array}{l}\text { Changes from the } \\
\text { development crisis }\end{array}$} & $\begin{array}{l}\text { My body is not the } \\
\text { same as before }\end{array}$ & $\begin{array}{l}\text { In the past, even if I jumped from a high wall, it fluttered, but now I'm } \\
\text { scared of people passing by. Now, if I fall, somewhere I break. }\end{array}$ \\
\hline & Loneliness & - I came home alone because I was bored. \\
\hline & & - My husband was teaching, but he went first. \\
\hline & & - I am going to go to a house where no one else is. \\
\hline \multirow[t]{2}{*}{$\begin{array}{l}\text { Freedom from the confines of } \\
\text { others' eye }\end{array}$} & $\begin{array}{l}\text { Solve meals without } \\
\text { noticing }\end{array}$ & $\begin{array}{l}\text { It's a sports-music and singing department, but I'm not coming to learn } \\
\text { songs. Give me rice for free. I can just eat one meal. Good! }\end{array}$ \\
\hline & $\begin{array}{l}\text { The joy of knowing } \\
\text { beyond religion }\end{array}$ & $\begin{array}{l}\text { I came because my friend asked me to go. I am not a member of the } \\
\text { church. It's Buddhism. Even if you are not a member of the church, the } \\
\text { pastor tells me a lot of good things before singing. There is a lot to learn! }\end{array}$ \\
\hline \multirow[t]{5}{*}{$\begin{array}{l}\text { Positive emotional } \\
\text { experiences found with } \\
\text { songs }\end{array}$} & Forming vitality of life & $\begin{array}{l}\text { Exercise-I am excited when a song I know in the music song department } \\
\text { comes out. If you sing along loudly, your vain heart will disappear. Less } \\
\text { sickness. }\end{array}$ \\
\hline & & - Living alone at home, what to do. \\
\hline & & I don't think it's useless. Come to charge energy. \\
\hline & $\begin{array}{l}\text { The joy of using leisure } \\
\text { time }\end{array}$ & $\begin{array}{l}\text { I feel good. When you hear the song. The ears are fun, the eyes are fun, } \\
\text { the mouths are fun for giving me something to eat. }\end{array}$ \\
\hline & & I don't have time when I'm at home. \\
\hline \multirow[t]{4}{*}{$\begin{array}{l}\text { Feeling the relationship with } \\
\text { your peers }\end{array}$} & $\begin{array}{l}\text { Thanks for taking care } \\
\text { of me }\end{array}$ & $\begin{array}{l}\text { That gray-haired grandmother takes care of me for a leg pain. Bring me } \\
\text { a cup of water and a copy of the song paper. How about in a restaurant. } \\
\text { She brings all the spoons on the plate. }\end{array}$ \\
\hline & & $\begin{array}{l}\text { It's better than a child because you take care of me for the first time. } \\
\text { Thank you and thank you. }\end{array}$ \\
\hline & Fear of future loss & $\begin{array}{l}\text { I haven't seen a grandmother taking care of me since last month. There } \\
\text { must be work. I was worried, but I asked the person I was with. He said } \\
\text { he was admitted to the hospital. I don't like he's going to go wrong. }\end{array}$ \\
\hline & Likes to be together & $\begin{array}{l}\text { I came because the local grandmothers told me to go. The pastor tells me a } \\
\text { lot of good things at the beginning of the exercise-music singing } \\
\text { department. It's better than staying at home alone. I have more my age } \\
\text { than the welfare center. }\end{array}$ \\
\hline \multirow[t]{3}{*}{ Change in self-awareness } & $\begin{array}{l}\text { A normal life like an } \\
\text { old man his age }\end{array}$ & $\begin{array}{l}\text { Everything is the same when talking about living here. It wasn't } \\
\text { bothersome to eat just me. }\end{array}$ \\
\hline & $\begin{array}{l}\text { Regain confidence and } \\
\text { confirm presence }\end{array}$ & $\begin{array}{l}\text { No one is interested in whether to enter or leave the house, but when you } \\
\text { come to the sports-music and singing. department, call me my name. I } \\
\text { don't even have a name tag. }\end{array}$ \\
\hline & & - Coming here gives me confidence, and always keep your thumb up. \\
\hline \multirow[t]{2}{*}{ Change the way of life } & $\begin{array}{l}\text { Enduring reality with } \\
\text { will and effort }\end{array}$ & I can eat and live. The waist is still healthy. \\
\hline & $\begin{array}{l}\text { Commitment to a life } \\
\text { that does its best }\end{array}$ & $\begin{array}{l}\text { It's fun so I don't worry about tomorrow. I have to live every day of my } \\
\text { life well. }\end{array}$ \\
\hline
\end{tabular}


by applying a phenomenological method to understand the meaning and essence of the sense of existence experienced by the elderly who participated in the exercise-music program of an elderly college.

The 1st category is 'Change from developmental crisis'. They complained of joint pain and low back pain due to aging, and said that even if a passerby touched them lightly, they would fall and break. The elderly subjects who participated in the exercise-music program had anxiety about injury due to their weakness physically and expressed depression mentally. He also said that he felt lonely when he entered an empty house due to the death of his spouse. In Park's research [14], the cause of the elderly's 'weakness' was viewed as a 'natural phenomenon of aging', and the energy of life was expressed as a feeling of exhaustion. In terms of physical health, it is common for the elderly to have more than one chronic disease. As he experienced changes in his body that could not function properly due to persistent chronic diseases and pain, the elderly were naturally exposed to being alone not only at night but also during the day. This is thought to have a negative effect on the emotions of the elderly the longer they spent time alone. The developmental crisis (aging) was similar to the findings of the study showing that it affected the body and mind. The death of a spouse and of a friend in the process of development in old age due to a change in life was expected and was not a general crisis situation. At this time, it is thought that the shock caused the person to become depressed and their self-esteem was threatened, and they experienced the absence of a sense of uselessness.

In Park's research [14], the elderly's weakness was described as 'a life sustained by someone's help', but the specific type of help was not described. Older people may feel depressed, appreciate the help around them, and feel a variety of emotions. Despite the pain, it was slightly relieved through the exercise-music program. The positive expression, 'It hurts my back, but I feel good when I sit down.' was different from those of the elderly who show aggression [15]. The difference between this study and other studies is that the elderly were depressed because of this weakness, and were negative because they were depressed with feelings of anger, but during the exercise-music program, they showed positive emotional changes and overcame negative emotions such as depression. The elderly in this study felt that they had regained their confidence and finally confirmed their presence. Therefore, the exercise-music program can change the emotional state of the elderly and should be con- tinuously intervened [16].

The 2 nd category of the exercise-music program experience derived in this study, 'Freedom from the confines of others', indicated that young people did not participate in the program to solve their meals, whereas the elderly did not have such gaze. 'It's an exercise-music song program, but I'm not coming to learn to sing. Come for lunch, give me rice for free, so come to get one meal!' This wasn't just an economic reason. In the study of Lee [17], it was shown that the results of the elderly learners breaking past egos and practices in online universities are similar.

The 3rd category, 'Positive emotions found through songs', includes a collection of 2 topics related to positive emotions: 'Building vitality in life' and 'The joy of using leisure time'. The elderly who participated in the study said that they received energy by listening to songs and singing along, and at that moment they felt less chronic pain and became cheerful. This is consistent with the report that participation in sports-music activities elicits positive emotional responses in the elderly [10]. In this study, the participant said, 'If you're alone at home, you can't do something because you think it's useless.' was expressed.

Finding meaning in life is said to have an unconditional meaning even in the state of suffering and death from various chronic diseases [18]. The will to seek meaning is a desire that anyone has, and this will and desire become the basic motive for human life. They have the freedom to choose a positive attitude, especially in painful situations, and this choice can be a healing power for the elderly. In domestic quantitative previous studies targeting the elderly, exercise-music programs were effective in reducing depression and enhancing self-esteem [19,20], improving self-efficacy in the elderly living alone [21], and significant results in the elderly's happiness [19,20-22] was also seen. In this study, when people come to senior college, they are not alone, and participation in the program appears to have a positive effect on the elderly who feel depression, anxiety, and helplessness. Therefore, it is considered necessary to use interventions because of good accessibility since the elderly participate in the sports-music program according to the characteristics of the elderly. On the other hand, in the study by Yoo and Kim [23], the elderly volunteers expressed 'The joy of rediscovered vitality.' as an essential theme, and volunteering without compensation was the joy of life for them. After all, they felt that volunteering was helped produce a sense of presence.

The 4th category, 'Feeling the relationship with your 
peers.', is a collection of three themes related to positive and negative emotions such as 'Thank you for caring for me.', 'Fear of loss in the future.', and 'Love to be together'. The elderly's appreciation tendency was significant in relationship satisfaction according to the level of burdensomeness [24]. This was shown to be similar to this study expressed as 'useless'.

In general, when someone is invisible, they worry, but they do not express fear of loss, whereas the participants in this study expressed fear. It is thought that they experienced negative emotions because they have already experienced loss of important people such as spouses and friends [25]. In Park's research [14], the state of health has changed due to sudden accidents such as falls and traffic accidents. Even during these programs, things can change at any time and therefore it is similar. There are things people can do on their own, but there are other things that need help. Intervention in senior college is meant to be done together, so if the Maslow's need stage theory [26] is applied, people want to have a sense of belonging through friendship, and in this affiliation it can create confidence through self-esteem and recognition of others, bringing a sense of accomplishment. The subjects of study preferred to be together rather than alone which was similar to the research results of Lee [27], who expressed that 'living together in the same space is a family'.

In the 5th category, 'Changes in self-awareness.', the senior citizens' college participants regained their confidence through an exercise-music program, which became an opportunity to be reborn as a 'useful person' and confirmed their presence. They said that they experienced a sense of accomplishment just by calling their name and that they restored their confidence through a sense of accomplishment. These results were consistent with a study [28] that found that elderly persons living alone felt a sense of presence when workers called them 'grandmother' or 'grandfather'. For the seniors in cyber college, the experience of learning is the past self, breaking customs, taking a new challenge, acquiring self-realization, and being integrated into a new identity, research that emerged as a future-oriented self [17]. Compared with the dynamics, it was possible to find a similarity with the study that when a person can develop themselves and lead the rest of their life, they can gain a sense of self and self-esteem [29]. This commonality seems to be related to the idea of not being a burden to one's children, especially without the help of others. In this study, unlike the result [15] that aggression-oriented elderly people are neg- ative due to remorse for life that is not respected, 'I feel good when I sit down, although my back hurts. When I come here, I feel confident.' This research method is similar, but this study included participants from a senior college operated by a religious facility, and it is thought that there is a difference because most of them were subjects of religion.

In the 6th category, 'Change of way of life' subjects experienced the experience of enduring reality with will and effort, and making a commitment to live day by day with their best effort. These results show that the lifestyles of the general elderly persons differ according to 'death awareness' and 'death meaning' [30]. Compared with the elderly's enjoyment beliefs and enjoyment styles in a positive relationship with the meaning of life [31], it is thought that the elderly's presence can be achieved only when there is a change in self-awareness. This study found that the exercise-music program not only confirmed one's presence, but also raised the level of life-style change. The weak elderly [14] said that they eventually crossed the recovery line and developed into a state in need of someone's help. The need for help meant that education at senior colleges can provide such assistance, so if an elderly person is in a community where lower body function enhancement, depression management programs, visiting services, and fall prevention management programs are not available, they can attend the exercise programs at senior colleges. As a result of this study, there was a positive effect of changing the way of life. Of course, the diversity of programs will need to be revised and supplemented, but if it is used well, it will be a suitable alternative to make up for the difficulties of COVID-19 during these times.

Since this study has a high proportion of music programs compared to exercise and was conducted in parallel with exercise and music, it is necessary to be cautious in generalizing the results. However, it is expected that this study will be used to understand the elderly's sense of presence and develop a program to restore their sense of achievement and confidence.

According to the results of this study, it was found that the elder's exercise-music program assisted in regaining confidence and confirming the presence of senior citizens. Although the meaning of presence may be different for each subject, it was a common wish to discover it. Therefore, 'valuelessness' can be an expression for the desire for presence, suggesting that it is necessary to increase their presence, especially for the positive emotions of the elderly. In addition, the exercise-music programs should be conducted 
continuously because the emotional state of the elderly can change. In the future, it is suggested to develop a variety of exercise-music programs for subjects who cannot even perform simple exercise programs due to physical constraints, and to repeat the research on a single exercise program.

\section{Conflict of Interest}

The authors declared no potential conflicts of interest with respect to the research, authorship, and/or publication of this article.

\section{References}

1. Statistics Korea. Total population and housing survey 2019. Daejeon: Statistics Korea; 2020.

2. Chang KO. Effect of self-esteem and life satisfaction on quality of life of elderly school program participants. J Korea Acad Ind Soc 2014;15:5078-87.

3. Kong HS, Lee MS. A study on the effects of the elderly's social support and self-esteem on the suicidal ideation. J Korean Soc Sch Health Educ 2012;13:113-25.

4. Fleming D. The meaning of lifelong learning in the lives of selected sages [Doctoral Dissertation]. Laramie (WY): University of Wyoming; 2000.

5. Gibson RC. Promoting successful and productive aging in minority populations. Paper presented at: 16th Vermont Conference on Primary Prevention of Psychopathology; 1993 Jun date; Burlington (VT), United States. p. 279-88.

6. Kim GY. The effect for the leisure activity program of Kyungrodang on life satisfaction and self-esteem of the senior: comparison of activity versus unactivity for the leisure activity program of Kyungrodang in Suwon city [Master thesis]. Suwon: Kyonggi University; 2005.

7. Lee B, Hong S. The effect of older people's leisure activities on their self-esteem and life satisfaction. Northeast Asia Tour Res 2012;8:139-56.

8. Lee YBN, Kim SJ. The use of music for healthy elderly: literature review. J Korea Contents Assoc 2016;16:335-46.

9. Beerens HC, Zwakhalen SMG, Verbeek H, E S Tan F, Jolani $\mathrm{S}$, Downs $\mathrm{M}$, et al. The relation between mood, activity, and interaction in long-term dementia care. Aging Ment Health 2018;22:26-32.

10. Huh J. An analysis of music education for elderly people in social education programs of senior welfare center [Master thesis]. Seoul: Ewha Womans University; 2010.

11. Saarikallio S. Music as emotional self-regulation throughout adulthood. Psychol Music 2011;39:307-27.

12. Hallam S, Creech A, Varvarigou M, McQueen H. Perceived benefits of active engagement with making music in community settings. Int J Community Music 2012;5:155-74.

13. Morse JM, Field PA. Qualitative research methods for health professionals. 2nd ed. Thousand Oaks (CA): Sage Publications; 1995.

14. Park JK. Experience of frailty in Korean elderly: a phenomenological study utilizing the Colaizzi method. J Korean Acad Nurs 2017;47:562-74.

15. Han JH, Kim EJ, Hyun JS, Kim N. The lived experience of anger in elderly women with aggressive tendency. J Korean Gerontol Nurs 2016;18:95-105.

16. Rho IG, Kang KS. Phenomenological research about chor music therapy for olderly women. Arts Hum 2019:5:43-64.

17. Lee EJ. Lived experience of older learners in an online university. J Korea Contents Assoc 2010;10:433-50.

18. Park SY. The relationships among importance, consistency of meaning in life and psychological health and the mediating effects of hope in the process of enhancing meaning in life. Cogn Behav Ther Korea 2016;16:213-31.

19. Kihl T, Chang S. A analysis on effect of rhythm action game for improvement of geriatric depression and self-esteem of elderly patients. J Korean Soc Comput Game 2012;25:93-103.

20. Yang HK. The effects of music psychotherapy programs upon the reduction of the depression of hemiplegia patients after. $\mathrm{J}$ Welf Aged 2010;49:127-144.

21. Kim CS. Study on the self-efficacy for older adults living alone using Pansori creative therapy program - focusing on vocal sound -. Korean J Music Ther Educ 2011;8:43-60.

22. Back SY. The effect of song focus music therapy program on the happiness and quality of life of the elderly. J Humanit Soc Sci 2017;8:869-85.

23. You JS, Kim KD. Continuous volunteering experience in elderly people: a phenomenological research. Korean J Soc Welf 2010; 62:247-70.

24. Han $\mathrm{M}$, Lee $\mathrm{S}$. The relationships among gratitude disposition, relational satisfaction, and mental well-being among the elderly: moderation effect of perceived burdensomeness. Korean $\mathbf{J}$ Gerontol Soc Welf 2017;72:35-60.

25. Choi M. The phenomenological research on elderly women's life experiences after the loss of their husbands through death at the older ages. J Welf Aged 2014;66:111-39.

26. Maslow AH. A theory of human motivation. Psychol Rev 1943; 50:370-96.

27. Lee JS. A qualitative study for co-habitation of the elderly living alone as familial alternative. J Asiat Stud 2015;58:42-71.

28. Nam SI, See J, Jung YE, Chae J. Meaning in life, depression, and suicidal ideation in old age: a comparative study of living alone and not living alone older adults. Korean J Gerontol Soc Welf 2019;74:163-92.

29. Kim J, Choi S, Hur J. A phenomenological research on social engagement experience of old people participating in circles. Korean J Gerontol Soc Welf 2017;72:37-67.

30. Lee JY, Rhee KO. A study on older adult's recognition of the death. J Korea Gerontol Soc 2004;24:193-215.

31. Jo EH, Lee YS. The relation between the meaning in life and savoring beliefs, ways of savoring in older adults: the mediating effect of cognitive emotion regulation strategies. J Rehabil Psychol $2013 ; 20: 565-85$ 